\title{
Graphene quantum dots combined with copper(II) ions as a fluorescent probe for turn-on detection of sulfide ions
}

\author{
Ningxiang $\mathrm{Yu}^{1} \cdot$ Hailong Peng ${ }^{1} \cdot \mathrm{Hua}$ Xiong ${ }^{1} \cdot$ Xiaqing $\mathrm{Wu}^{2} \cdot$ Xiaoyan $\mathrm{Wang}^{2}$ • \\ Yanbin $\mathrm{Li}^{3,4} \cdot$ Lingxin Chen ${ }^{2}$
}

Received: 1 April 2015 / Accepted: 16 June 2015 /Published online: 2 July 2015

(C) Springer-Verlag Wien 2015

\begin{abstract}
A fluorescent probe for the sensitive and selective determination of sulfide ions is presented. It is based on the use of graphene quantum dots (GQDs) which emit strong and stable blue fluorescence even at high ionic strength. Copper(II) ions cause aggregation of the GQDs and thereby quench fluorescence. The GQDs-Cu(II) aggregates can be dissociated by adding sulfide ions, and this results in fluorescence turn on. The change of fluorescence intensity is proportional to the concentration of sulfide ions. Under optimal conditions, the increase in fluorescence intensity on addition of sulfide ions is linearly related $\left(r^{2}=0.9943\right)$ to the concentration of sulfide ions in the range from 0.20 to $20 \mu \mathrm{M}$, and the limit of detection is $0.10 \mu \mathrm{M}$ (at $3 \sigma / \mathrm{s})$. The fluorescent probe is highly selective for sulfide ions over some potentially interfering ions. The method was successfully applied to the determination of sulfide ions in real water samples and gave recoveries between 103.0 and $113.0 \%$.
\end{abstract}

Hua Xiong

huaxiong100@126.com

Lingxin Chen

1xchen@yic.ac.cn

1 State Key Laboratory of Food Science and Technology, Nanchang University, Nanchang 330047, People's Republic of China

2 Key Laboratory of Coastal Environmental Processes and Ecological Remediation, Yantai Institute of Coastal Zone Research, Chinese Academy of Sciences, Yantai 264003, China

3 College of Biosystems Engineering and Food Science, Zhejiang University, Hangzhou 310058, China

4 Department of Biological and Agricultural Engineering, University of Arkansas, Fayetteville, AR 72701, USA
Keywords Graphene quantum dots · Copper(II) ions · Fluorescent probe $\cdot$ Sulfide ions · Quenching $\cdot$ Fluorescence recovery

\section{Introduction}

Graphene, a one-atom thick and two-dimensional honeycomb lattice of sp2 hybridized carbon atoms, has achieved great interest within the scientific research in recent years. Graphene is a promising step for future nanodevices because of its properties, such as large surface area, good electronic transportation, superior mechanical flexibility, energy-storage media, and environmental friendly nature [1-5]. A new kind of zerodimensional fluorescent material called graphene quantum dots (GQDs) is obtained when the graphene sheet is smaller than $100 \mathrm{~nm}$ [6]. As a new kind of luminescent carbon nanomaterial, GQDs have a superior chemical inertness, higher surface area, and larger diameter compared with conventional QDs and carbon dots [7]. Due to the pronounced quantum confinement and edge effects, GQDs possess high photoluminescence, slow hotcarrier relaxation, and useful in the construction of nanoscale optical and electronic devices [8, 9]. Importantly, the carboxylic acid moieties at the edge impart GQDs with excellent water solubility, which eases the function with various organic, polymeric, inorganic or biological species [10]. In addition, the low toxicity and good biocompatibility of GQDs have been reported $[11,12]$. These distinct advantages make GQDs have a great promising material to replace the commonly used semiconductor nanocrystals for a number of optical biosensing and bioimaging related applications [13-15].

The concentration of sulfide ions is an important environmental index, because sulfide ions have a lethal property at high concentrations [16]. Moreover, sulfide ions can irritate mucous membranes and even have an extreme action on the 
nerve system, which cause unconsciousness and respiratory paralysis [17]. In addition, sulfide ions levels are related to various diseases, such as Alzheimer's disease [18], Down's syndrome [19], and liver cirrhosis [20]. Therefore, developing a rapid and sensitive method for monitoring sulfide ions is highly important to ensure human health safety. Great progress has been made regarding sulfide ions detect devices in the past several years, such as chromatography [21], titration [22], extraction [23], fluorimetry [24], spectrophotometry [25], and an electrochemical method [26]. Considering practicality and convenience, fluorimetry method is acceptable. Thus, many fluorescent probes have been reported recently for the detection of sulfide ions.

Sulfide ions can react with copper ions to form stable $\mathrm{CuS}$ species, which has a low-solubility product constant $\left(\mathrm{k}_{\mathrm{sp}}=\right.$ $\left.6.3 \times 10^{-36}\right)$. With this property, we designed a GQDs-Cu ${ }^{2+}$ system that acts as an effective fluorescent probe for sulfide ions detection in water. The oxygen-containing groups on the GQDs surface can interact with $\mathrm{Cu}^{2+}$ ions, leading to fluorescence quenching of the GQDs [27]. When sulfide ions were added to the assay solution, a turn on fluorescence signal was detected. The change of fluorescence intensity was proportional to the concentration of sulfide ions. Thus, the on-offon switching in the fluorescence of GQDs was expected to provide a quantitative determination of sulfide ions in water samples.

\section{Experimental}

\section{Reagents}

$\mathrm{Hg}\left(\mathrm{NO}_{3}\right)_{2}, \mathrm{AgNO}_{3}, \mathrm{Cd}\left(\mathrm{NO}_{3}\right)_{2}, \mathrm{Mn}\left(\mathrm{NO}_{3}\right)_{2}, \mathrm{FeCl}_{3}, \mathrm{BaCl}_{2}$, $\mathrm{AlCl}_{3}, \mathrm{MgCl}_{2}, \mathrm{ZnCl}_{2}, \mathrm{CaCl}_{2}, \mathrm{KCl}, \mathrm{NH}_{4} \mathrm{Cl}, \mathrm{Na}_{2} \mathrm{~S}, \mathrm{CuCl}_{2}$, $\mathrm{NaF}, \mathrm{NaCl}, \mathrm{NaBr}, \mathrm{NaI}, \mathrm{NaClO}, \mathrm{CH}_{3} \mathrm{COONa}, \mathrm{NaNO}_{2}$, $\mathrm{NaNO}_{3}, \mathrm{Na}_{2} \mathrm{CO}_{3}, \mathrm{Na}_{2} \mathrm{HPO}_{4}, \mathrm{Na}_{2} \mathrm{SO}_{4}, \mathrm{Na}_{2} \mathrm{SO}_{3}, \mathrm{Na}_{2} \mathrm{~S}_{2} \mathrm{O}_{3}$, $\mathrm{NaSCN}, \mathrm{NaOH}, \mathrm{H}_{3} \mathrm{BO}_{3}$, and $\mathrm{Na}_{2} \mathrm{~B}_{4} \mathrm{O}_{7} \cdot 10 \mathrm{H}_{2} \mathrm{O}$ were obtained from Sinopharm Chemical Reagent (Shanghai, China) (http://www.sinoreagent.com/). $\mathrm{H}_{2} \mathrm{SO}_{4}$ and $\mathrm{HNO}_{3}$ were purchased from Yantai Shuangshuang Chemical Co., Ltd (Yantai, China) (http://shuang-pla.51pla.com/). Graphene oxide (GO) was purchased from SXFNANO Materials Tech Co., Ltd (Nanjing, China) (http://graphene.cn.china.cn/). All other chemical agents used were of analytical grade and used without further purification.

\section{Synthesis of graphene quantum dots}

GQDs were synthesized according to previously described methods [27]. In summary, GO $(5 \mathrm{mg})$ reacted with concentrated $\mathrm{H}_{2} \mathrm{SO}_{4}(30 \mathrm{~mL})$ and $\mathrm{HNO}_{3}(10 \mathrm{~mL})$ for $5 \mathrm{~h}$ under ultrasonic conditions using the ultrasonic cleaner. To obtain a solid product, the suspension was diluted with distilled water
$(250 \mathrm{~mL})$ and centrifuged for $15 \mathrm{~min}(10464.48(\times \mathrm{g}))$. The solid product was redispersed in distilled water $(50 \mathrm{~mL})$, and the $\mathrm{pH}$ was adjusted to 12 with $\mathrm{NaOH}$. The suspension was moved into a poly(tetrafluoroethylene) (Teflon)-lined autoclave $(100 \mathrm{~mL})$ and heated at $180^{\circ} \mathrm{C}$ for $10 \mathrm{~h}$. After cooling at room temperature, the black suspension was filtered through a $0.22 \mu \mathrm{m}$ microporous membrane to obtain a pellucid filtered solution. The filtrated solution was dialyzed using the dialysis bag (8000-14000 Da) for $24 \mathrm{~h}$. Consequently, blue fluorescent GQDs were achieved.

\section{Characterization}

Fourier transform infrared (FT-IR) spectra were recorded using an FT-IR spectrophotometer (Nicolet 5700, Thermo Electron Corporation, MA, USA) at resolution of $4 \mathrm{~cm}^{-1}$ in the range of $600-4000 \mathrm{~cm}^{-1}$. UV-vis absorption spectra were recorded on a Thermo Scientific NanoDrop 2000/2000C spectrophotometer (USA) using a $1 \mathrm{~cm}$ path length quartz cell. Zeta potential and size distribution were measured using a Malvern Zeta/sizer Nano-ZS90 (ZEN3590). Transmission electron microscopy (TEM) analyses were performed on a JEM-1230 electron microscope (Japan) operating at $100 \mathrm{KV}$. The TEM samples were prepared by drying a droplet of GQDs solution on a $\mathrm{Cu}$ grid. Fluorescence intensity was recorded on the luminescence spectrometer (Perkin-Elmer LS-55, PerkinElmer Instruments, UK). Raman spectra were collected using INVIA spectrophotometer (Renishaw, UK) with the excitation wavelength at $514 \mathrm{~nm}$.

\section{Procedure for detecting sulfide ions}

GQDs $\left(20 \mu \mathrm{L}, 80 \mu \mathrm{g} \mathrm{mL}^{-1}\right), \mathrm{CuCl}_{2}(10 \mu \mathrm{L}, 1 \mathrm{mM})$ were mixed with boron boric acid buffer $(40 \mathrm{mM}, \mathrm{pH} 7.0$, $960 \mu \mathrm{L}$ ) and incubated for $1 \mathrm{~min}$ to obtained the GQDs$\mathrm{Cu}^{2+}$ system. Different concentrations of sulfide ions $(10 \mu \mathrm{L})$ were added into the GQDs- $\mathrm{Cu}^{2+}$ system and incubated for $1 \mathrm{~min}$. The fluorescent intensity of the resulting solution was recorded from 380 to $600 \mathrm{~nm}$ through excitation with $320 \mathrm{~nm}$ light. The spectral bandwidths were set as $5 \mathrm{~nm}$. The procedure of sulfide ions detection was conducted at room temperature.

\section{Selectivity and interference of probe}

Sulfide ions $(10 \mu \mathrm{L}, 20 \mu \mathrm{M})$ and these potentially interfering ions $\left(\mathrm{SCN}^{-}, \mathrm{S}_{2} \mathrm{O}_{3}{ }^{2-}, \mathrm{SO}_{3}{ }^{2-}, \mathrm{SO}_{4}{ }^{2-}, \mathrm{PO}_{4}{ }^{3-}, \mathrm{CO}_{3}{ }^{2-}, \mathrm{NO}_{3}{ }^{-}\right.$, $\mathrm{NO}_{2}{ }^{-}, \mathrm{AC}^{-}, \mathrm{ClO}^{-}, \mathrm{I}^{-}, \mathrm{Br}^{-}, \mathrm{Cl}^{-}$, and $\left.\mathrm{F}^{-}\right)(10 \mu \mathrm{L}, 200 \mu \mathrm{M})$ were added into the GQDs- $\mathrm{Cu}^{2+}$ system, respectively, and then the fluorescence spectra were detected for investigation the selectivity of probe. For interference experiment, sulfide ions $(10 \mu \mathrm{L}, 20 \mu \mathrm{M})$ were added into the GQDs- $\mathrm{Cu}^{2+}$-anion system, and the fluorescence spectra were detected. 


\section{Analysis of sulfide ions in water samples}

Drinking water and tap water samples were obtained from a local water supply system, and were filtered through a $0.22 \mu \mathrm{m}$ membrane. Water samples were spiked with known concentrations of sodium sulfide solutions following the standard addition method. The spiked samples were then added into the GQDs- $\mathrm{Cu}^{2+}$ system, and the fluorescence spectra were detected.

\section{Results and discussion}

\section{Characterization of graphene quantum dots}

The structure of GQDs and GO were characterized via FT-IR, and the results are shown in Fig. 1a. Compared with the spectrum of GO, the band of carboxyl $\left(1728 \mathrm{~cm}^{-1}\right)$ and hydroxyl groups $\left(3413 \mathrm{~cm}^{-1}\right)$ of GQDs dramatically decreased, and the epoxy groups (1369-1057 $\mathrm{cm}^{-1}$ ) almost disappeared. These results suggest that a few oxygen-containing functional groups were destroyed during the reaction, and the GO were changed into small photoluminescent species [28]. The Raman spectroscopy of the GQDs (Fig. 1b) shows the partially disordered crystal structure of GQDs that the scattering at the edges caused [29].

The UV-vis absorption spectrum and fluorescence emission spectra of GQDs are shown in Fig. 1c. The GQDs solution has a broad absorption with a weak shoulder at approximately $300 \mathrm{~nm}$. These results are consistent with those from a previous report [27]. The fluorescence spectrum of the GQDs has a strong speak at $427 \mathrm{~nm}$ when the excitation was $320 \mathrm{~nm}$. Similar to most fluorescent carbon-based nanomaterials, GQDs possessed the property of excitation-dependent fluorescence behavior. As shown in Fig. 1c, the fluorescence spectrum peaks of the GQDs shift from 427 to $436 \mathrm{~nm}$ with the excitation wavelength increasing from 320 to $350 \mathrm{~nm}$. This excitation-dependent fluorescence behavior may result from the optical selection of differently sized GQDs and surface defects of GQDs [30]. As shown in the inset, the GQDs exhibit an intense blue fluorescence color under irradiation with $365 \mathrm{~nm}$ UV light.

To determine the stability of GQDs under a highly ionic strength environment, the fluorescence of GQDs was measured in a solution of $40 \mathrm{mM}$ boron boric acid buffer ( $\mathrm{pH} 7.0$ ) containing different concentrations of $\mathrm{NaCl}$. Figure 1d shows that GQDs have stable fluorescence even under high ionic strength conditions and the quenching effect of $\mathrm{Cu}^{2+}$ was weakened with the increasing concentration of
Fig. 1 a FT-IR spectra of GO (a) and GQDs $(b)$. b Raman spectrum of GQDs. c UV/Vis absorption and PL spectra of GQDs at different excitation wavelengths (Inset: photographs of an aqueous solution of the GQDs under $365 \mathrm{~nm}$ UV light and visible light). $\mathbf{d}$ The influence of $\mathrm{NaCl}$ concentration $(0,200,400,600$, $800,1000 \mathrm{mM}$ ) on GQDs and the probe fluorescence a

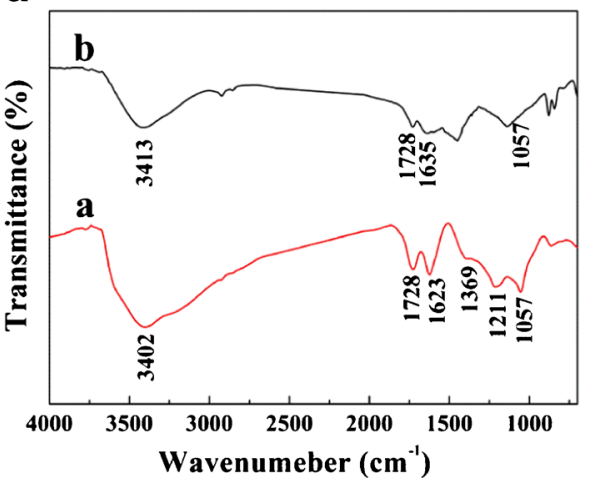

C

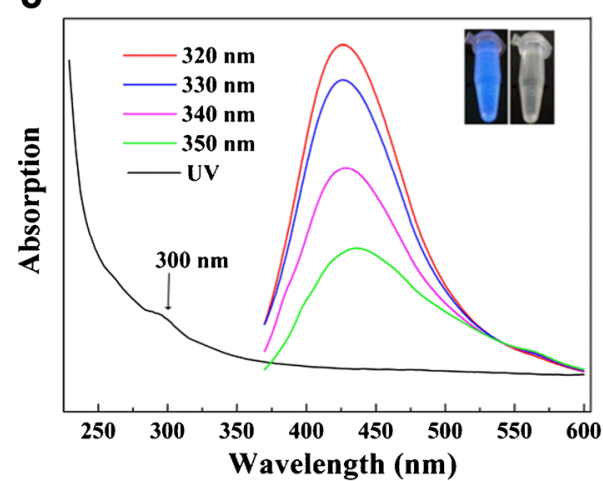

b

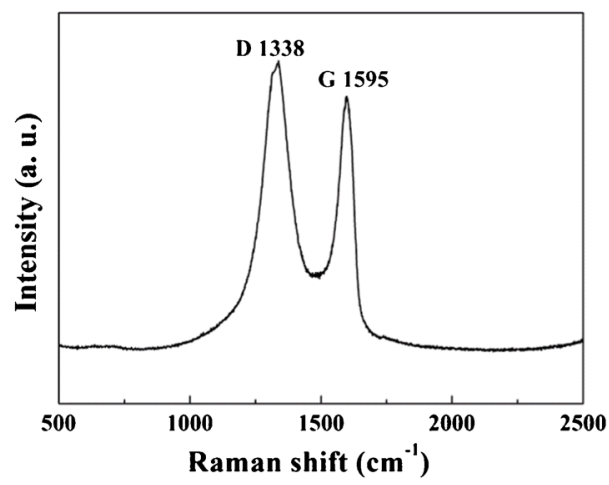

d

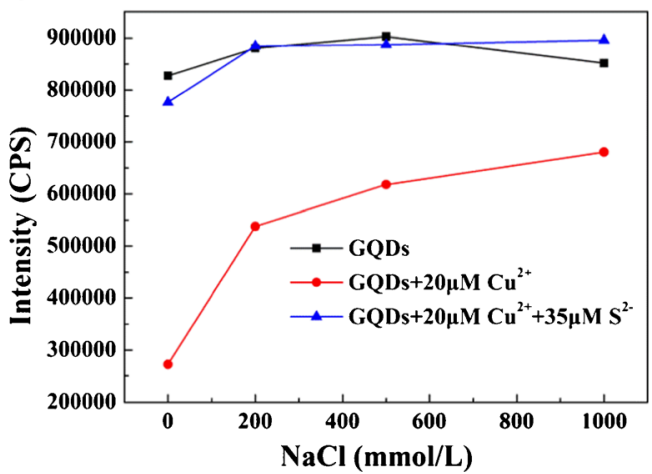




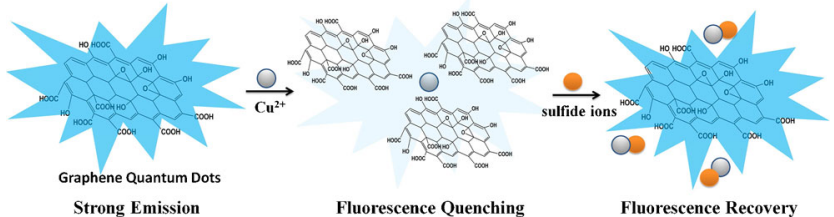

Scheme 1 Schematic illustration of the preparation processes of sulfide ions detection based on GQDs- $\mathrm{Cu}^{2+}$ systems

$\mathrm{NaCl}$. This finding suggests that GQDs have a great potential for sensing applications under complicated conditions.

\section{Detection principle for sulfide ions}

As shown in Scheme 1, GQDs with many oxygen-containing groups act as the electron donors. $\mathrm{Cu}^{2+}$ ions can easily combine with the oxygen-containing groups, which functions as the bridge for the resulting in GQDs aggregation. Consequently, the fluorescence of GQDs was quenched through energy or electron transfer process from the GQDs to $\mathrm{Cu}^{2+}$ ions. Sulfide ions then had a higher affinity for the electron donors atoms in $\mathrm{Cu}^{2+}$ ions than oxygen-containing groups, leading to the dissociation of the GQDs aggregation and the fluorescence was turn on. At that time, the intensity enhancement of the GQDs was directly related to the amount of sulfide ions added to the GQDs aggregation solution. Thus, the on-off-on switching in the fluorescence of GQDs was expected to provide a quantitative determination of sulfide ions in water samples.

To confirm this principle, transmission electron microscopy (TEM), size distribution and Zeta potential were performed. Figure 2 shows the morphology and size distribution of GQDs, GQDs aggregates, and GQDs- $\mathrm{Cu}^{2+}$ system with sulfide ions. Figure 2 a shows that the GQDs were monodispersed in pure water with an average diameter of $20.22 \mathrm{~nm}$ (Fig. 2d). The GQDs aggregated when $\mathrm{Cu}^{2+}$ ions were added (Fig. 2b), and the average diameter increased to $483.02 \mathrm{~nm}$ (Fig. 2e). However, the GQDs aggregates are redispersed and the average diameter decreased to $28.53 \mathrm{~nm}$ when sulfide ions were added (Fig. 2c and f). The zeta potentials of GQDs, GQDs aggregates, and GQDs- $\mathrm{Cu}^{2+}$ system with sulfide ions were $-33.80,-13.20$, and $-34.10 \mathrm{mV}$, respectively. These results confirmed that $\mathrm{Cu}^{2+}$ can make the GQDs aggregate and the $\mathrm{Cu}^{2+}$ induced GQDs aggregation can be destroyed after introducing sulfide ions.

\section{Optimization of experimental conditions}

To obtain the best detecting conditions, potential effects of relevant experimental parameters, including the $\mathrm{pH}$, quenching effect of different metal ions, and concentrations of $\mathrm{Cu}^{2+}$ were evaluated.
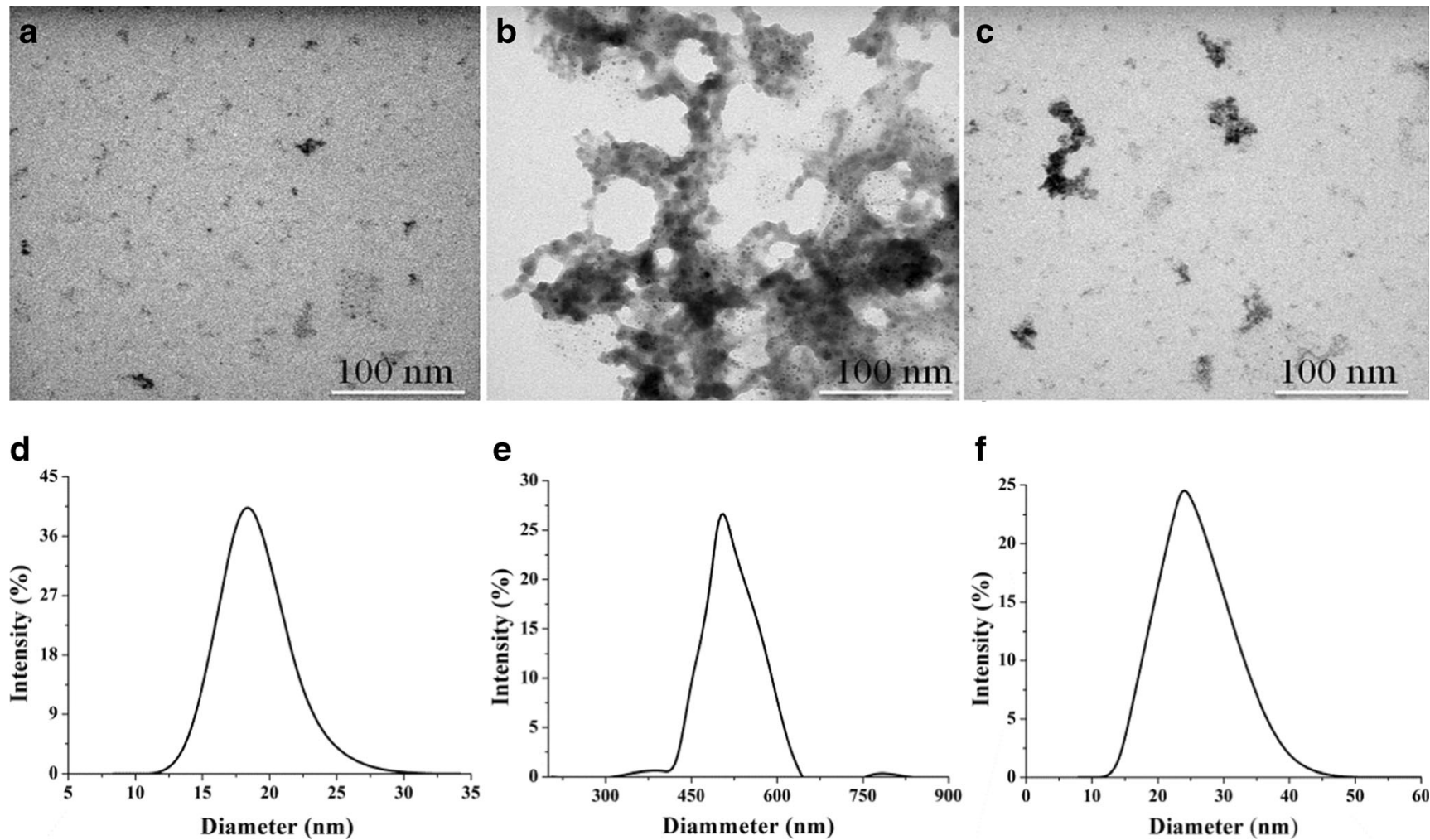

Fig. 2 TEM images: GQDs dispersed in pure water (a), GQDs with addition of $20 \mu \mathrm{M} \mathrm{Cu}^{2+}$ ions (b), and GQDs with addition of $20 \mu \mathrm{M}$ $\mathrm{Cu}^{2+}$ ions and $30 \mu \mathrm{M}$ sulfide ions (c). Size measurements: GQDs

dispersed in pure water (d), GQDs with addition of $20 \mu \mathrm{M} \mathrm{Cu}^{2+}$ ions (e), and GQDs with addition of $20 \mu \mathrm{M} \mathrm{Cu}^{2+}$ ions and $30 \mu \mathrm{M}$ sulfide ions (f) 
Fig. 3 a Fluorescence quenching of the GQDs with addition of $\mathrm{Cu}^{2+}$ ions $(10 \mu \mathrm{M})$ in different $\mathrm{pH}$ buffer solutions. b Fluorescence quenching of the GQDs with addition of different ions (all ions were at $20 \mu \mathrm{M}) . F$ and $F_{0}$ are the fluorescence intensity of the GQDs in the presence and absence of different cations, respectively. c Fluorescence quenching of the GQDs with addition of different concentrations of $\mathrm{Cu}^{2+}$ ions in buffer solution ( $\mathrm{pH} 7.0,40 \mathrm{mM}$ ). The $\mathrm{Cu}^{2+}$ ions concentrations are $0,1,4,7,10,20,40,80$ and $200 \mu \mathrm{M}$, respectively. (Inset: fluorescence intensity change at $430 \mathrm{~nm}$ as addtion with $\mathrm{Cu}^{2+}$ ions from 0 to $200 \mu \mathrm{M}) . F$ and $F_{0}$ are the fluorescence intensity of the GQDs in the presence and absence of $\mathrm{Cu}^{2+}$ ions, respectively a

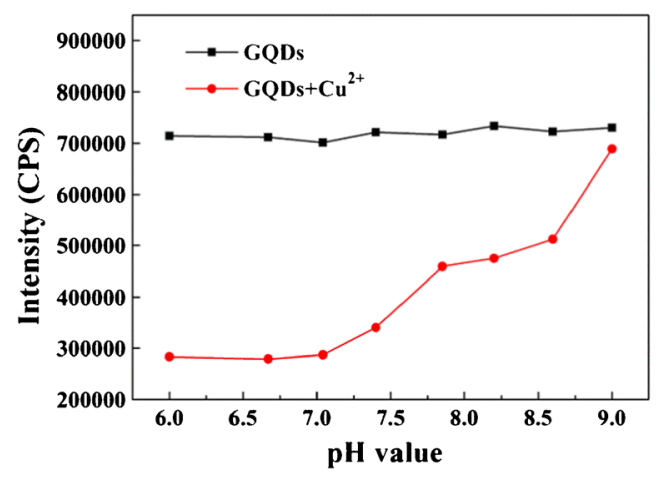

b

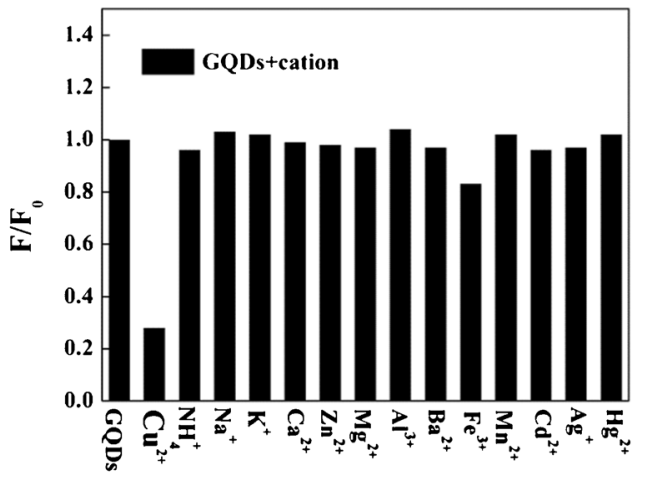

\section{C}

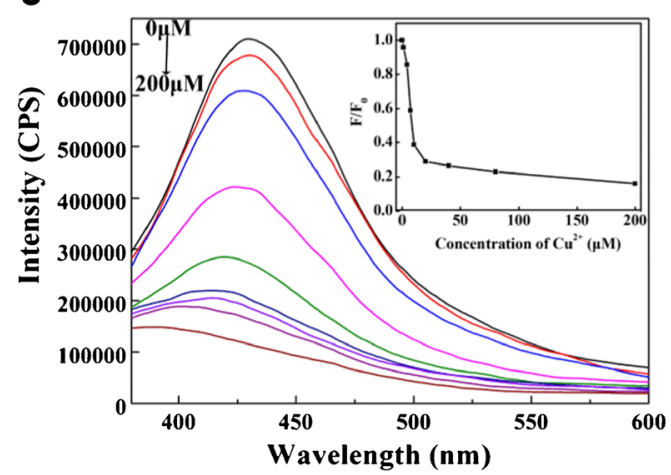

Figure $3 \mathrm{a}$ shows that this fluorescence probe is $\mathrm{pH}$-dependent. This result can be ascribed to two reasons. First, the carboxylate groups on the surface of GQDs would be deprotonated in a basic solution, leading to electrostatic repulsion between the GQDs, and preventing the formation of GQDs- $\mathrm{Cu}^{2+}$ aggregates. Second, $\mathrm{Cu}^{2+}$ reacted with $\mathrm{OH}^{-}$and formed $\mathrm{Cu}(\mathrm{OH})_{2}$ at alkaline conditions, and prevented the coordination of $\mathrm{Cu}^{2+}$ ions to the oxygen-containing groups of GQDs. Thus, $\mathrm{Cu}^{2+}$ ions cannot quench the fluorescent intensity of GQDs at alkaline conditions. Therefore, the pH 7.0 buffer solution is chosen to obtain high sensitivity and wide linear range.

The quenching effect of different cations, including $\mathrm{Cu}^{2+}$, $\mathrm{NH}_{4}^{+}, \mathrm{Na}^{+}, \mathrm{K}^{+}, \mathrm{Ca}^{2+}, \mathrm{Zn}^{2+}, \mathrm{Mg}^{2+}, \mathrm{Al}^{3+}, \mathrm{Ba}^{2+}, \mathrm{Fe}^{3+}, \mathrm{Mn}^{2+}$, $\mathrm{Cd}^{2+}, \mathrm{Ag}^{+}$, and $\mathrm{Hg}^{2+}$ were investigated. $\mathrm{Cu}^{2+}$ ions have the highest quenching ability for the fluorescence of the GQDs, and $\mathrm{Fe}^{3+}$ ions have a slight quenching effect (Fig. 3b). Meanwhile, other ions show little quenching of fluorescence of the a

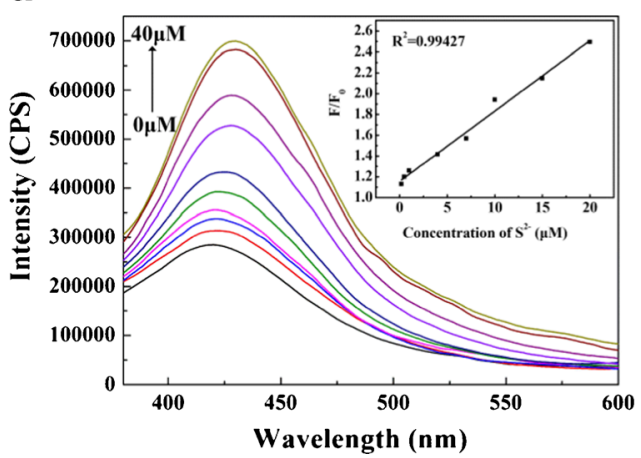

Fig. 4 a Fluorescence intensity recovery of GQDs- $\mathrm{Cu}^{2+}$ systems with addition of different concentrations of sulfide ions in buffer solution $(\mathrm{pH} 7.0,40 \mathrm{mM})$. The concentrations of sulfide ions are $0,0.20,0.50$, $1,4,7,10,15,20$, and $40 \mu \mathrm{M}$, respectively. (Inset: Stern-Volmer plot of $F / F_{0}$ recovery at $430 \mathrm{~nm}$ of GQDs-Cu ${ }^{2+}$ systems with addition of sulfide b

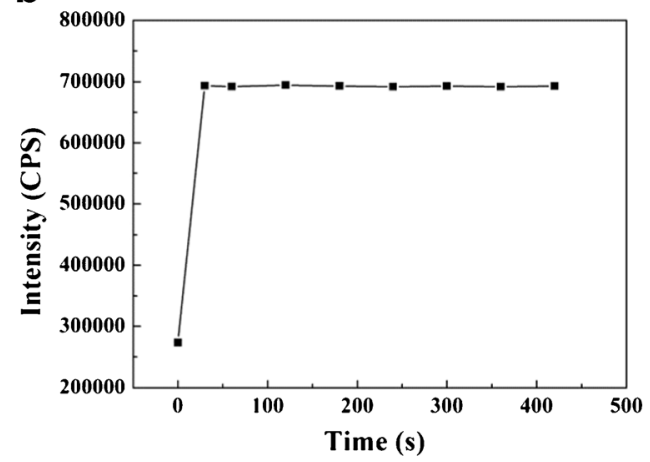

ions from 0.20 to $20 \mu \mathrm{M}$ ). $F$ and $F_{0}$ are the fluorescence intensity of the GQDs- $\mathrm{Cu}^{2+}$ systems in the presence and absence of sulfide ions, respectively. b Time-dependent fluorescence intensity recovery of GQDs- $\mathrm{Cu}^{2+}$ systems with addition of sulfide ions (sulfide ions were at $20 \mu \mathrm{M})$ in buffer solution ( $\mathrm{pH} 7.0,40 \mathrm{mM}$ ) 
Table 1 Comparison of optical methods reported in the literature for determination of sulfide ions

\begin{tabular}{lllcc}
\hline Analytical technique & Sample matrix & $\mathrm{LDR}^{1}(\mu \mathrm{M})$ & LOD $^{2}(\mu \mathrm{M})$ & Reference \\
\hline Colorimetric probe $^{\mathrm{a}}$ & River and tap water & $12.00-50.00$ & 8.10 & {$[31]$} \\
Colorimetric probe $^{\mathrm{b}}$ & River water & $20-100.00$ & 10.00 & {$[32]$} \\
Fluorescent probe $^{\mathrm{c}}$ & Tap and river water & $1.35-10.00$ & 1.35 & {$[33]$} \\
Fluorescent probe $^{\mathrm{d}}$ & Tap and Ground water & $1.20-26.00$ & 0.33 & {$[24]$} \\
Fluorescent probe $^{\mathrm{e}}$ & Running water & $5.00-35.00$ & 0.15 & {$[34]$} \\
Fluorescent probe $^{\mathrm{f}}$ & Environmental water & $3.10-56.30$ & 6.50 & {$[35]$} \\
This method & Tap water and drinking water & $0.20-20.00$ & 0.10 & This work \\
\hline
\end{tabular}

${ }^{\text {a }}$ Copper nanoparticles

${ }^{\mathrm{b}}$ Gold nanorods (GNRs) nonaggregation-based colorimetric probe

c Benzimidazole-based flurescent chemosensor

d Zinc sulfide quantum dots doped with manganese

${ }^{\text {e }}$ Dinitrobenzenesulfonate ester coupled with poly(ethylene glycol)

${ }^{\mathrm{f}}$ Functionalized CdS quantum dots

${ }^{1}$ Linear dynamic range

${ }^{2}$ Limit of detection

GQDs. The selectivity quenching may be ascribed to the fact that $\mathrm{Cu}^{2+}$ ions have a strong affinity toward the oxygencontaining groups on the GQDs surface than other metal ions [27]. Therefore, $\mathrm{Cu}^{2+}$ ions were selected as the optimal quenching ion.

The effect of the $\mathrm{Cu}^{2+}$ concentration on fluorescence intensity of GQDs is shown in Fig. 3c. The results indicated that the fluorescence intensity of GQDs gradually decreased as the $\mathrm{Cu}^{2+}$ ions concentration increased. The results also indicated that the $F / F_{0}$ value rapidly decreased from 100 to $62.50 \%$ with increasing $\mathrm{Cu}^{2+}$ ions concentration from 0 to $10 \mu \mathrm{M}$, and then tended to slowly decrease. Thus, $10 \mu \mathrm{M} \mathrm{Cu}^{2+}$ ions were used in the following experiments.

\section{Quantitative determination of sulfide ions}

At optimized conditions, the fluorescence intensity recovery efficiency of GQDs- $\mathrm{Cu}^{2+}$ systems in the presence of sulfide ions with different concentrations were recorded. The fluorescence intensity of GQDs- $\mathrm{Cu}^{2+}$ systems gradually recovered through adding sulfide ions with concentrations ranging from 0.20 to $40 \mu \mathrm{M}$ (Fig. 4a). The inset image indicates that a good linear relationship exists, which ranges from 0.20 to $20 \mu \mathrm{M}$ with a high correlation coefficient $\left(r^{2}=0.9943\right)$. The linear regression equation and detection limit $(3 \sigma / \mathrm{s})$ for sulfide ions were $F / F_{0}=0.06763 x+1.15668$ and $0.10 \mu \mathrm{M}$, respectively. In addition, the fluorescence intensity recovery of the GQDs$\mathrm{Cu}^{2+}$ systems with sulfide ions was completed within $30 \mathrm{~s}$ (Fig. 4b). Moreover, the detection limits are low enough to detect common levels of sulfide ions in water. The detection limits and linear ranges for sulfide ions in this method were compared with other previously reported optical probes, and the results are listed in Table 1. Our method was significantly more sensitive than previous optical probes.

\section{Selectivity and interference of this probe}

The selectivity and interference of this probe were investigated as shown in Fig. 5. Sulfide ions can significantly restore the fluorescence intensity of the GQDs- $\mathrm{Cu}^{2+}$ systems but no clear enhancement is observed with potentially interfering ions. The results indicated that GQDs- $\mathrm{Cu}^{2+}$ system based fluorescence sensing is highly selective for sulfide ions. The possible interference of these potentially interfering ions was also

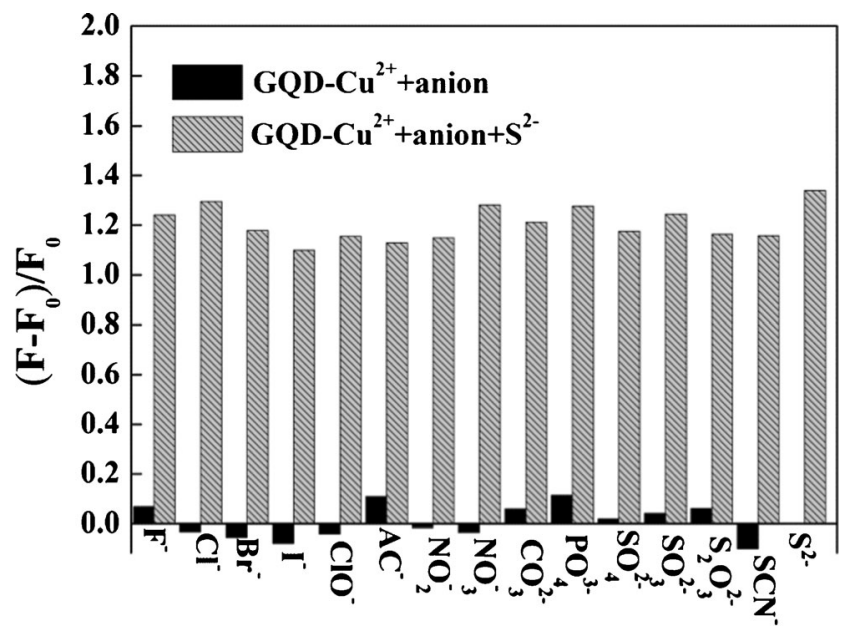

Fig. 5 Selectivity and interference of GQDs-Cu ${ }^{2+}$ systems in buffer solution $(\mathrm{pH} 7.0,40 \mathrm{mM})$ towards other anions. The concentrations of sulfide ions and each of the other anions are 20 and $200 \mu \mathrm{M}$, respectively. $F$ and $F_{0}$ stand for the fluorescence intensity of the GQDs- $\mathrm{Cu}^{2+}$ systems in the presence and absence of other anions, respectively 
Table 2 Determination results of sulfide ions in water samples by using GQDs- $\mathrm{Cu}^{2+}$ based

fluorometric sensors ${ }^{\text {a }}$

\begin{tabular}{lcccc}
\hline Samples & $\begin{array}{l}\text { Added sulfide } \\
\text { ions }(\mu \mathrm{M})\end{array}$ & $\begin{array}{l}\text { Measured sulfide } \\
\text { ions }(\mu \mathrm{M})\end{array}$ & $\begin{array}{l}\text { Recovery } \\
(\%)\end{array}$ & $\begin{array}{l}\text { RSD } \\
(\%)\end{array}$ \\
\hline Tap water & 1.00 & 1.13 & 113.00 & 2.34 \\
& 7.00 & 7.40 & 105.70 & 1.79 \\
Drink water & 15.00 & 15.50 & 103.30 & 1.45 \\
& 1.00 & 1.11 & 110.00 & 2.38 \\
& 7.00 & 7.33 & 104.71 & 1.21 \\
& 15.00 & 15.45 & 103.00 & 0.74 \\
\hline
\end{tabular}

a The standard deviation was obtained by three measurements evaluated. The results showed that these potentially interfering ions only have a small effect on the fluorescence intensity of GQDs- $\mathrm{Cu}^{2+}$-sulfide systems. These good properties imply that the proposed method can be applied for the detection of sulfide ions in water samples.

\section{Detection of sulfide ions in water samples}

This probe was investigated to detect sulfide ions in water samples. The results are shown in Table 2 . The recovery of spiked sulfide ions ranged from 103.00 to $113.00 \%$. The relative standard deviation (RSD) was lower than $2.50 \%$. The results indicated that the probe is applicable for quantifying sulfide ions in water samples.

\section{Conclusions}

We demonstrated a GQDs- $\mathrm{Cu}^{2+}$ system for the detection of sulfide ions in water samples with rapid, sensitivity and selectivity. This method is achieved based on the fact that $\mathrm{Cu}^{2+}$ can quench fluorescence intensity of GQDs, and the addition of sulfide ions can make it recovers. This method has several advantages: (1) The detection method has a wide linearity from 0.20 to $20 \mu \mathrm{M}$ with a sensitive detection limit of $0.10 \mu \mathrm{M}(3 \sigma / \mathrm{s})$. (2) The detection method is highly selective for sulfide ions, and these potentially interfering ions only have a small interference on the fluorescence intensity. (3) This probe is rapid with a response time of less than $30 \mathrm{~s}$. (4) The GQDs is an environment friendly material and has stable fluorescence intensity even with high ionic strength. (5) This probe is simple in design and has been successfully applied to detect sulfide ions in tap water and drink water. We envision that this method was promising applications for further applications.

Acknowledgments This work was supported by the National Key Technology Research and Development Program of the Ministry of Science and Technology of China (2013BAD19B02), the National Natural Science Foundation of China $(21266020,21201098,31160317$ and
21275158), the Natural Science Foundation of Jiangxi Province (20142BAB213003 and 20151BAB203029), and Jiangxi Department of Education Fund (GJJ13039).

\section{References}

1. Geim AK, Novoselov KS (2007) The rise of graphene. Nat Mater 6: 183-191

2. Rao CNR, Sood AK, Subrahmanyam KS, Govindaraj A (2009) Graphene: the new two-dimensional nanomaterial. Angew Chem Int Ed 48:7752-7777

3. Geim AK (2009) Graphene: status and prospets. Science 324: $1530-1534$

4. Allen MJ, Tung VC, Kaner RB (2010) Honeycomb carbon: a review of graphene. Chem Rev 110:132-145

5. Blake P, Brimicombe PD, Nair RR, Booth TJ, Jiang D, Schedin F, Ponomarenko LA, Morozov SV, Gleeson HF, Hill EW, Geim AK, Novoselov KS (2008) Graphene-based liquid crystal device. Nano Lett 8:1704-1708

6. Ponomarenko LA, Schedin F, Katsnelson ML, Yang R, Hill EW, Novoselov KS, Geim AK (2008) Chaotic dirac billiard in graphene quantum dots. Science 320:356-358

7. Shen JH, Zhu YH, Yang XL, Li CZ (2012) Graphene quantum dots: emergent nanolights for bioimaging, sensors, catalysis and photovoltaic devices. Chem Commun 48:3686-3699

8. Bacon M, Bradley SJ, Nann T (2014) Graphene quantum dots. Part Part Syst Charact 31:415-428

9. Mueller ML, Yan X, McGuire JA, Li LS (2010) Triplet states and electronic relaxation in and photoexcited graphene quantum dots. Nano Lett 10:2679-2682

10. Qi YX, Zhang M, Fu QQ, Liu R, Shi GY (2013) Highly sensitive and selective fluorescent detection of cerebral lead(II) based on graphene quantum dot conjugates. Chem Commun 49:1059910601

11. Zheng XT, Than A, Ananthanaraya A, Kim DH, Chen P (2013) Graphene quantum dots as universal fluorophores and their use in revealing regulated trafficking of insulin receptors in adipocytes. ACS Nano 7:6278-6286

12. Zhu SJ, Zhang JH, Qiao CY, Tang SJ, Li YF, Yuan WJ, Li B, Tian L, Liu F, Hu R, Gao HN, Wei HT, Zhang H, Sun HC, Yang B (2011) Strongly green-photoluminescent graphene quantum dots for bioimaging applications. Chem Commun 47:6858-6860

13. Ju J, Chen W (2014) Synthesis of highly fluorescent nitrogendoped graphene quantum dots for sensitive, label-free detection of $\mathrm{Fe}(\mathrm{III})$ in aqueous media. Biosens Bioelectron 58:219-225 
14. Ran X, Sun HJ, Pu F, Ren JS, Qu XG (2013) Ag nanoparticledecorated graphene quantum dots for label-free, rapid and sensitive detection of $\mathrm{Ag}^{+}$and biothiols. Chem Commun 49:1079-1081

15. Zhang L, Zhang ZY, Liang RP, Li YH, Qiu JD (2014) Boron-doped draphene quantum dots for selective glucose sensing based on the "Abnormal" aggregation-induced photoluminescence enhancement. Anal Chem 86:4423-4430

16. Chen WY, Lan GY, Chang HT (2011) Use of fluorescent DNAtemplated gold/silver nanoclusters for the detection of sulfide ions. Anal Chem 83:9450-9455

17. Jiménez D, Martínez-Máñez R, Sancenón F, Ros-Lis JV, Benito A, Soto J (2003) A new chromo-chemodosimeter selective for sulfide anion. J Am Chem Soc 125:9000-9001

18. Eto K, Asada T, Arima K, Makifuchi T, Kimura H (2002) Brain hydrogen sulfide is severely decreased in alzheimer's disease. Biochem Biophys Res Commun 293:1485-1488

19. Kamoun P, Belardinelli MC, Chabli A, Lallouchi K, ChadefauxVekemans B (2003) Endogenous hydrogen sulfide overproduction in down syndrome. Am J Med Genet 116:310-311

20. Łowicka E, Bełtowski J (2007) Hydrogen sulfide $\left(\mathrm{H}_{2} \mathrm{~S}\right)$-the third gas of interest for pharmacologists. Pharmacol Rep 59:4-24

21. Rocklin RD, Johnson EL (1983) Determination of cyanide, sulfide, iodide, and bromide by ion chromatography with electrochemical detection. Anal Chem 55:4-7

22. Balasubramanian S, Pugalenthi V (2000) A comparative study of the determination of sulphide in tannery waste water by ion selective electrode (ISE) and iodimetry. Water Res 34:4201-4206

23. Allen HE, Fu GM, Deng BL (1993) Analysis of acid-volatile sulfide (AVS) and simultaneously extracted metals (SEM) for the estimation of potential toxicity in aquatic sediments. Environ Toxicol Chem 12:1441-1453

24. Rajabi HR, Shamsipur M, Khosravi AA, Khani O, Yousefi MH (2013) Selective spectrofluorimetric determination of sulfide ion using manganese doped $\mathrm{ZnS}$ quantum dots as luminescent probe. Spectrochim Acta A 107:256-262

25. Zhang ZY, Chen ZP, Wang SS, Qu CL, Chen LX (2014) On-site visual detection of hydrogen sulfide in air based on enhancing the stability of gold nanoparticles. ACS Appl Mater Interfaces 6:63006307
26. Lawrence NS, Deo RP, Wang J (2004) Electrochemical determination of hydrogen sulfide at carbon nanotube modified electrodes. Anal Chim Acta 517:131-137

27. Wang FX, Gu ZY, Lei W, Wang WJ, Xia XF, Hao QL (2014) Graphene quantum dots as a fluorescent sensing platform for highly efficient detection of copper(II) ions. Sensors Actuators B Chem 190:516-522

28. Bai JM, Zhang L, Liang RP, Qiu JD (2013) Graphene quantum dots combined with europium ions as photoluminescent probes for phosphate sensing. Chem Eur J 19:3822-3826

29. Gupta V, Chaudhary N, Srivastava R, Sharma GD, Bhardwaj R, Chand S (2011) Luminscent graphene quantum dots for organic photovoltaic devices. J Am Chem Soc 133:9960-9963

30. Cai F, Liu XD, Liu S, Liu H, Huang YM (2014) A simple one-pot synthesis of highly fluorescent nitrogen-doped graphene quantum dots for the detection of $\mathrm{Cr}(\mathrm{VI})$ in aqueous media. RSC Adv 4: 52016-52022

31. Hatamie A, Zargar B, Jalali A (2014) Copper nanoparticles: a new colorimetric probe for quick, naked-eye detection of sulfide ions in water samples. Talanta 121:234-238

32. Liu JM, Wang XX, Li FM, Lin LP, Cai WL, Lin X, Zhang LH, Li ZM, Lin SQ (2011) A colorimetric probe for online analysis of sulfide based on the red shifts of longitudinal surface plasmon resonance absorption resulting from the stripping of gold nanorods. Anal Chim Acta 708:130-133

33. Tang LJ, Cai MJ, Huang ZL, Zhong KL, Hou SH, Bian YJ, Nandhakumar R (2013) Rapid and highly selective relay recognition of $\mathrm{Cu}$ (II) and sulfide ions by a simple benzimidazole-based fluorescent sensor in water. Sensors Actuators B Chem 185:188194

34. Zheng F, Wen M, Zeng F, Wu S (2013) A water-soluble, lowcytotoxic and sensitive fluorescent probe based on poly (ethylene glycol) for detecting sulfide anion in aqueous media and imaging inside live cells. Polymer 54:5691-5697

35. Gore AH, Vatre SB, Anbhule PV, Han SH, Patil SR, Kolekar GB (2013) Direct detection of sulfide ions $\left[\mathrm{S}^{2-}\right]$ in aqueous media based on fluorescence quenching of functionalized CdS QDs at trace levels: analytical applications to environmental analysis. Analyst 138:1329-1333 